\title{
Conceptual Design of a Body Bag for Preventing Infections and Safe Disposal of Deceased from COVID-19 Virus
}

\author{
Mayank Patel $^{1}$. Shubham Khatri ${ }^{1}$. Jyoti Ratna Shree ${ }^{2} \cdot$ Anand S. Patil $^{3} \cdot$ Pooja Agrawal $^{3} \cdot$ Ashesha Sinha $^{3}$. \\ Mrinal Dubey ${ }^{3} \cdot$ Reema Mittal $^{3} \cdot$ Avinash K. Agarwal $^{1,3}$
}

Received: 15 May 2020 / Revised: 9 June 2020 / Accepted: 13 June 2020 / Published online: 24 June 2020

(c) Indian National Academy of Engineering 2020

\begin{abstract}
The Covid-19 virus pandemic is leading to a large number of deaths. There are forecasts that there will be an exponential increase in the number of such deaths across the globe because of this deadly virus. To arrest the spread of the virus in this situation, the supply of medical materials including PPE and body bags (also known as human remains pouch or cadaver bag) should be designed to stop the spread of the Covid-19 virus. Conventional body bags have shortcomings, which need to be addressed by a refined redesigning and use of appropriate materials to adequately match the requirements in the current Covid-19 situation. Current designs of the body bags do not allow the family member's sentiments towards the deceased and to cater to the desire of the family members to view the face of the deceased without exposing them to a strong possibility of infection from the cadaver. This is, therefore, a very traumatic experience to the family and in many cases, the cadaver is not handled with respect due to the unavailability of safe design body bags, which also exposes health workers to avoidable risk from the infections. Technopark @iitk has proposed an integrated 5-layer body bag to tackle this situation for Covid-19 deceased such that it is (1) leak-proof, (2) impermeable/water-proof, (3) strong enough for the purpose, (4) ergonomically designed, and (5) has provision to view the face of the dead body for family viewing before cremation/burial. This new design would keep the handling of the deceased body to a minimum during transportation from the hospital/site of death to a mortuary, and then to the home of the deceased/burial ground/crematorium, where it may be disposed-off along with the body in it, in a respectable manner, without putting people involved to the risk of infection.
\end{abstract}

Keywords Body bag $\cdot$ Covid-19 $\cdot$ Cadaver $\cdot$ Body disposal $\cdot$ Infections

\section{Introduction}

The recent outbreak of the Covid-19 virus has startled the world. The causative agent is a virus that phylogenetically belongs to the SARS-CoV clade and it is called 'severe acute respiratory syndrome coronavirus-2' (SARS-CoV-2) (Gorbalenya et al. 2020). This is a large family of enveloped, positive-sense single-stranded Ribonucleic acid (RNA) viruses that affect the respiratory tract of humans (Cascella et al.

Avinash K. Agarwal

akag@iitk.ac.in

1 Indian Institute of Technology Kanpur, Kanpur 208016, India

2 National Institute of Fashion Technology, New Delhi 110016, India

3 IIT Kanpur Research and Technology Park (Technopark@ Iitk), Kanpur 208016, India
2020; 2020a). In the case of a healthy person affected by the Covid-19 virus, who does not have any underlying medical condition (such as diabetes, respiratory issues, hypertension and cardiac problems), it shows mild flu-like symptoms that can be cured with medication for cold and fever (2020b, c). However, elderly people and those with compromised immunity can succumb to this disease by developing Acute Respiratory Distress Syndrome (ARDS) and pneumonia, which could be fatal (Cascella et al. 2020; 2020a). To date, there is no specific medicine or vaccine for Covid-19 virus (WHO 2020).

World health organization (WHO) report based on current evidence and literature suggests that the transmission of the Covid-19 virus primarily occurs through respiratory droplets (World Health Organization 2020). It can also happen through contact with fomites since the virus persists and are viable on various surfaces for up to 3-4 days (World Health Organization 2020; van Doremalen et al. 2020). Other modes 
of transmission could be 'air-borne' in special circumstances and settings that generate aerosols (World Health Organization 2020) and through faeces (Wang et al. 2020). Given the highly contagious nature of the Covid-19 virus, the world is grappling with death incidences, and $~ 7 \%$ fatality of the world-wide infected cases have been reported already (Collins 2013). This number of Covid-19 related deaths is increasing rapidly in India (2020d) as well as around the globe, particularly, in the US, Spain, Russia, UK, Italy, Brazil, France, which are a few worst-affected countries with 500,000 citizens projected to die worldwide amid this coronavirus outbreak (2020e; f). This coronavirus pandemic has severely impacted the supply chain, resulting in severe shortages in critical medical supplies (Key Points 2016). British Broadcasting Corporation (BBC) reports that UK health services are finding it difficult to meet the demands of body bags (also known as 'human remains pouch' or 'cadaver pouch') with the increased cases of Covid-19 virus fatality and it is in the process of procurement from a supplier in Canada (2020g). In such a scenario where Covid-19 is not going away anytime soon, and demands related to public health and health caretakers is also going to soar around the world, the resolve of self-reliant India by the Government of India (GOI) (2020h) with the vision to 'turn crisis into opportunity' is the only way to scurry out of this ordeal.

To date, there is no evidence of SARS-CoV-2 transmission from deceased bodies. Though, there is a possibility of live virus persistence in the lungs of the deceased body, if the person died due to the infectious of Covid-19 virus (WHO Interm Guidance 2020). It is only through improper handling during autopsy or contact through spillage of bodily fluid, it can be infectious (WHO Interm Guidance 2020). To maintain precaution from the risk of the body fluids and secretions, both the national and international regulators' have formulated guidelines on 'dead body management', where they instruct the use of leak-proof impermeable body bag (WHO Interm Guidance 2020; Ministry of Health \& Family Welfare 2020; European Centre For Disease Prevention and Control 2020). The body bag material, therefore, has to be more than just plastic and able to contain virulent micro-organisms. The majority of conventional body bags that are available in the market are unable to stop leakage of blood and body fluid. Also, the presence of fluid around the deceased body can weaken the integrity of the body bag, which can potentially cause the body bag to tear upon handling. Since these body bags are not impermeable hence there is also an increased possibility of the cadaver kept inside the bag to rapidly decompose on exposure to micro-organisms from the surrounding environment during storage. Moreover, if a body bag is fabricated with a weak design, the bearers themselves may have to support the weight of the cadaver by placing their hands under the body bag, beneath the cadaver, making transportation of the body bag more difficult and simultaneously increasing the risk of contamination/infection. Besides, the passing away of a dear one has a significant place in all cultures and across geography - there are sentiments of family members and relatives attached with the deceased, which needs to be taken into consideration, when handling and preparing the dead body for its disposal (Bedford 2018). For this, the family and near ones should be allowed to view the face of the dead body without exposing them to the risk of infection.

Currently, very few companies in India and abroad are manufacturing body bags that incorporate all the abovementioned features to qualify as a proper Covid-19 response body bag. To address this shortcoming, Technopark@iitk has designed an integrated layered body bag. A 5-integrated layered body bag with six handles of webbing strips will give ease of handling and safety to all those involved in dead body management and disposal following religious protocols. It will also minimize the movement of the deceased body during transportation from the site of death to the mortuary and to the home/crematorium/burial site, where it could be disposed-off along with the dead body inside it.

\section{Design of Body Bag}

There are different types of body bags available in the market (2020i). Out of these, a vertical centre zipper arrangement is normally used in body bags. Centre zipper is placed on the upper front, which ensures ease of body's entry and removal process. The other type of bag employs a U-shaped zipper, which is produced with less stitching than the central zipper and is low-cost as well. Inserting a body in U shaped zipper arrangement is quite simple as compared to centre zipper arrangement because of less body contact needed in U-shaped due to its openness.

Single-layer body bag has issues related to body fluid leakage, tearing of the bag due to handling, which particularly needs to be avoided while handling a deceased body of a Covid-19 virus patient. A new integrated multi-layered body bag with 6 webbings is a better option compared to existing 2- or 3-layer design. The new design offers several benefits as listed below:

1. Novel design especially is specifically designed for Covid-19 infected deceased that require bio-safety level (BSL) 3 and 4 (2019).

2. Conventional body bags may have a chance of body fluid leakage, which is completely avoided in the existing design because of use of a bottom padding layer of a super absorber polyurethane (PU) base, a cotton sheet layer, and two consecutive transparent plastic wraps.

3. A special provision is made to see the face of the deceased, to respect the sentiments of the family mem- 
bers and their desire to see the face of the deceased in their difficult times, whilst ensuring their safety. Due to this provision, there is no need to open the body bag, once it is packed and disinfected by mortuary staff in the hospital.

4. High-density polyethylene (HDPE) is used for the construction because it has superior tensile strength compared to low-density polyethylene (LDPE), which is used as inner layers in the production of existing body bags (2020j). HDPE ensures a better weight handling capacity of the new design of the body bag.

5. Some of the existing cadaver bags have webbings, a total of 2 or 4 in number. To ensure that the bodyweight is better distributed over the entire length of the body bag,

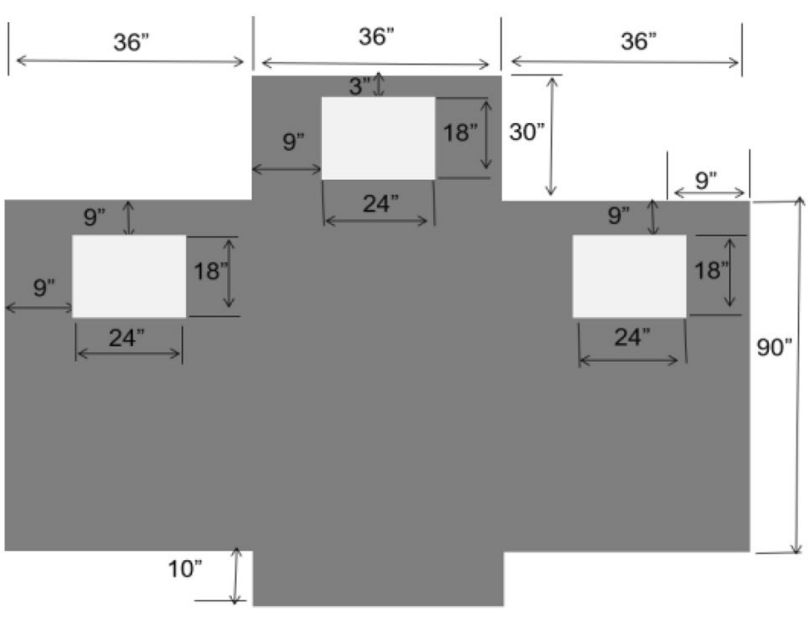

Fig. 1 Block pattern diagram for a body bag

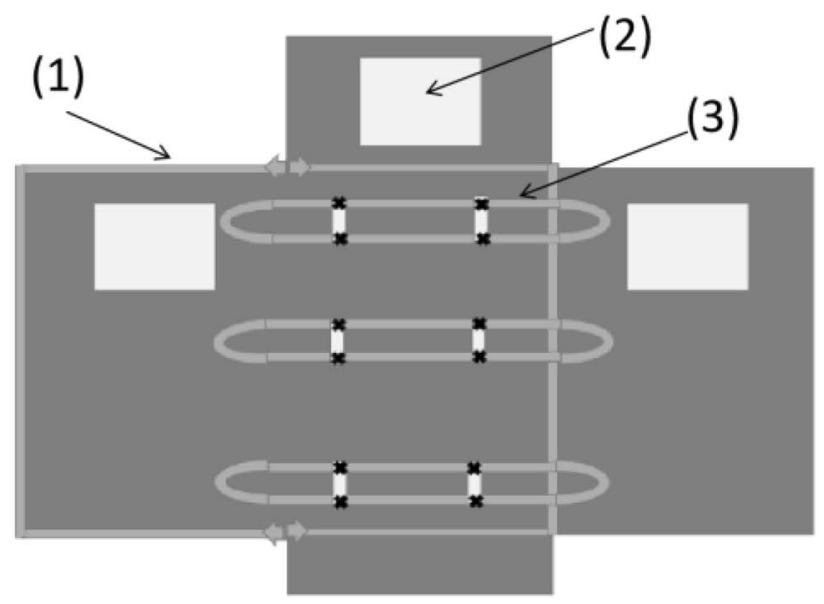

(a)
6 webbings have been included in this design, for ensuring easier transportation of cadaver in the body bag.

The following are the steps to make a body bag, which also show its design concept:

Step 1 Cut $130 " \times 108 "$ piece of an HDPE [100-300 g/ $\mathrm{m}^{2}$ (gsm)] or Polyethylene Vinyl Acetate (PEVA) $(0.2 \mathrm{~mm}$ thick) material according to the given measurements in the prototype dimension of Fig. 1, three windows are cut for transparent rectangular windows (Dimensions may be modified later, subject to size-set ratio). Transparent plastics are used for making these three windows for face viewing.

Step 2 This step involves the insertion of a U-shaped zipper on one side of the pattern (the left panel) along with the attachments of webbing strips as shown in Fig. 2.

Step 3 A PU Foam of 0.5 in. of $90^{\prime \prime} \times 36^{\prime \prime}$ is taken to fix at the centre of the block pattern. Along with it, the Velcro tapes are attached as per predefined places shown in Fig. 3, i.e. one on both sides of $90^{\prime \prime}$ foam, positioning 50" above the bottom. The other two velcros must be sewed at 40" downside at the height of $10^{\prime \prime}$ above the bottom. An additional Velcro should be placed at the center of $36^{\prime \prime}$ base. This qualifies our fixation of foam base to cover the body.

Step 4 Two pairs of transparent plastic sheets of dimensions $90^{\prime \prime} \times 36^{\prime \prime}$ and $60^{\prime \prime} \times 36^{\prime \prime}$ with two rounded corners on only one side as given in Fig. 4 are cut. The first plastic layer is supposed to be placed on either side of the PU foam layer as shown in Fig. 5a. Velcro tapes are attached as per the earlier step which is shown in Fig. 5b. The second pair of plastic layers is supposed to be fixed on each side as shown in Fig. 6a. Thus two alternative pairs of plastic layers facilitate the prevention of any cross aerosol contamination.

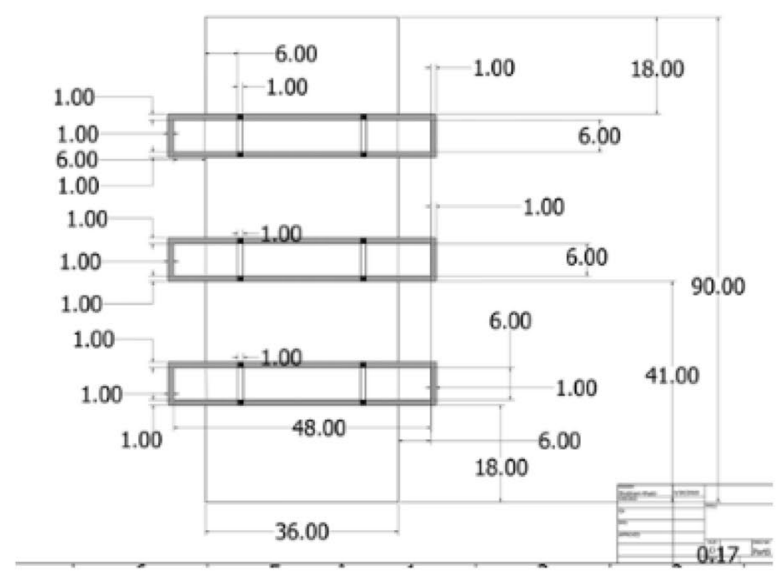

(b)

Fig. 2 a 1 stand for $U$ shaped zipper, 2 for transparent windows, and 3 for webbing strips attachment on block pattern and $\mathbf{b}$ dimension of webbing strips and its arrangement 


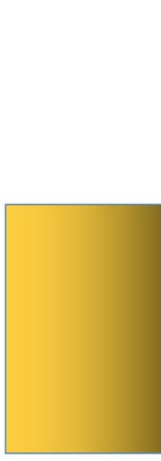

(a)

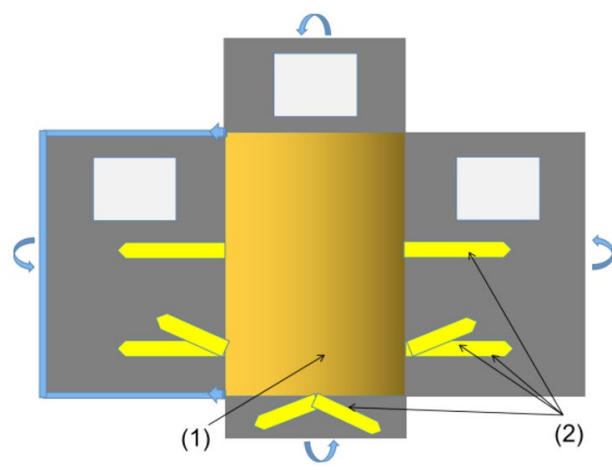

(b)
Fig. 3 a Polyurethane foam layer and $\mathbf{b}$ Attachment of PU foam layer shown as 1 and four Velcro tapes as 2 on block pattern
Step 5 Attach Velcro tapes as per earlier procedure on the second pair of the transparent plastic layer as shown in Fig. 6b. Now comes the cotton sheet layer, which has to be of $60^{\prime \prime} \times 24^{\prime \prime}$ with two rounded corners on one side as per Fig. $7 \mathrm{a}$ and another panel can be traced as the mirror image. Both panels are supposed to be attached on both sides of the 90" side of PU foam as shown in Fig. 7b. This cotton sheet layer shall cover the body below the neck. This is the end of this bag making process, and thus the integrated body bag is ready to use.

\section{Guidelines for Use}

The User Guide consists of a step-by-step procedure to use this integrated body bag, which gives sufficient locking capability. There is a total of 14 steps, as shown in Table 1. While following these steps, health workers must

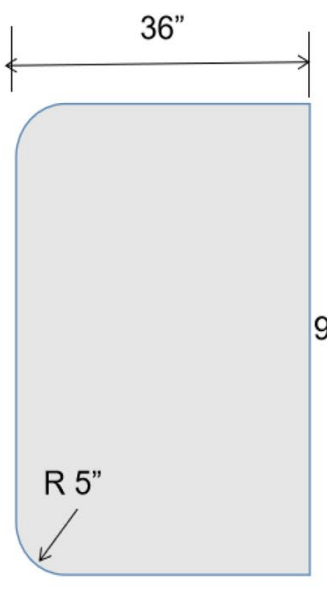

(a)

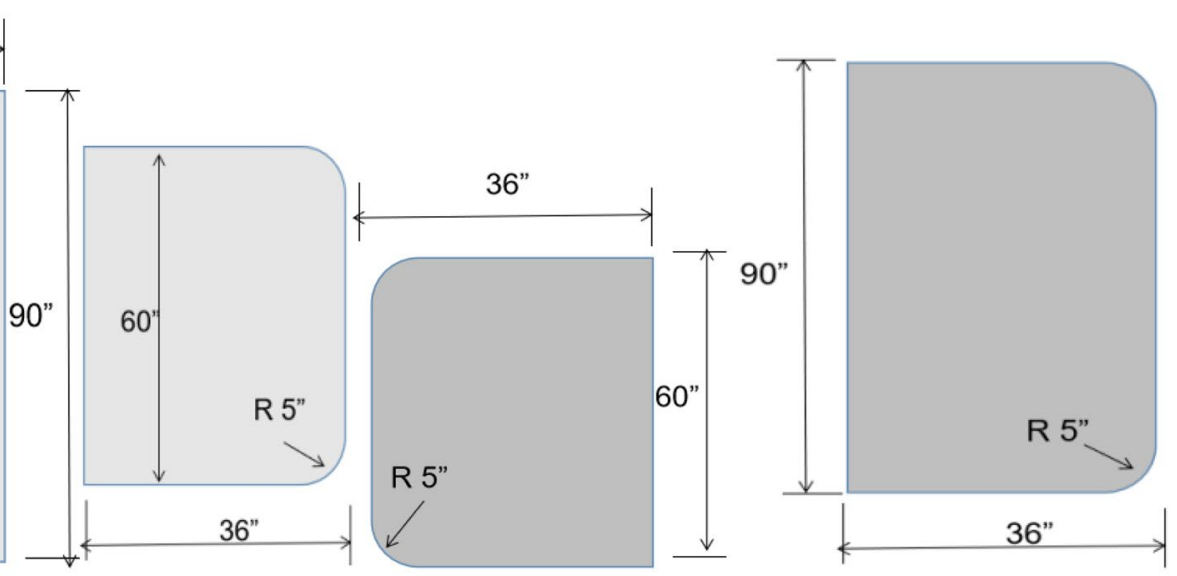

(b)

Fig. 4 Dimension of a one pair of the transparent plastic layers, $\mathbf{b}$ dimension of the second pair of plastic layers

Fig. 5 Attachment of a one pair of transparent plastic layer, $\mathbf{b}$ Velcro tapes on a plastic layers

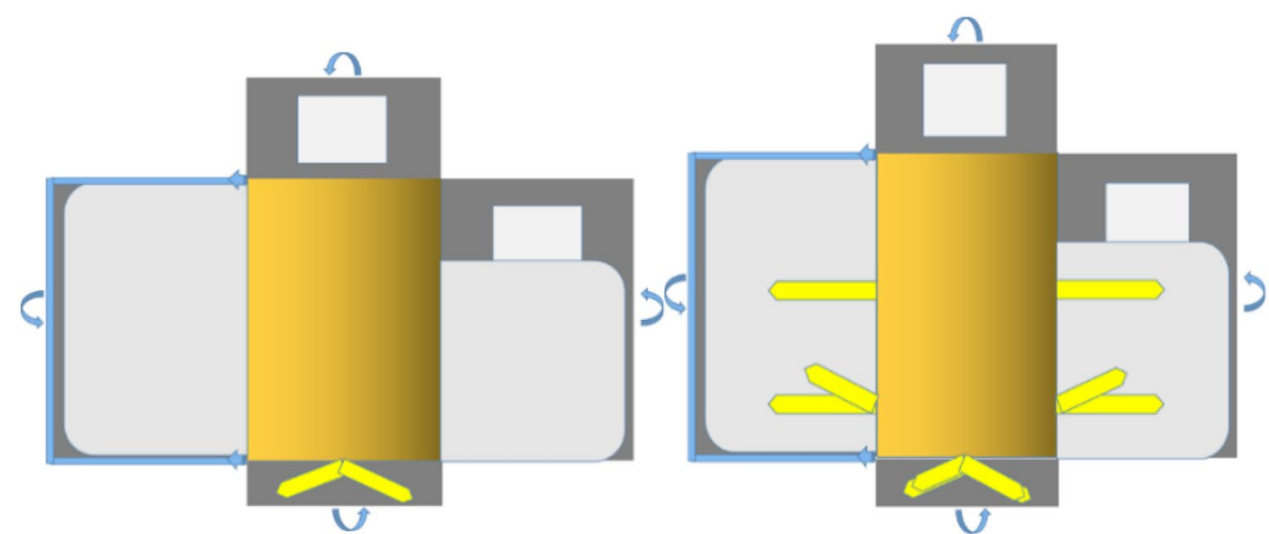

(a)

(b) 
Fig. 6 Attachment of a the second pair of the transparent plastic layer, b Velcro tapes on plastic layers

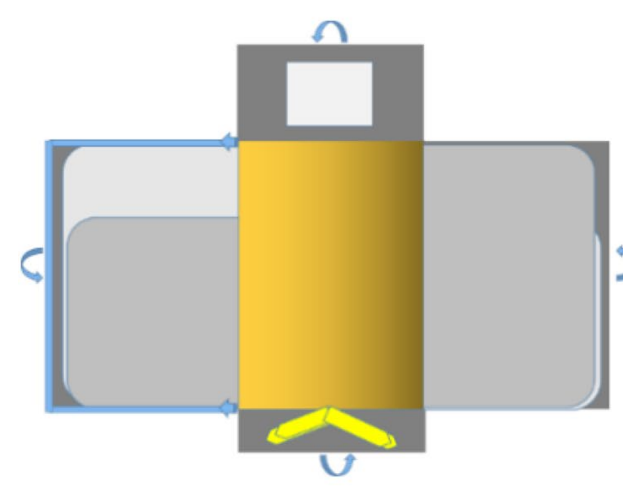

(a)

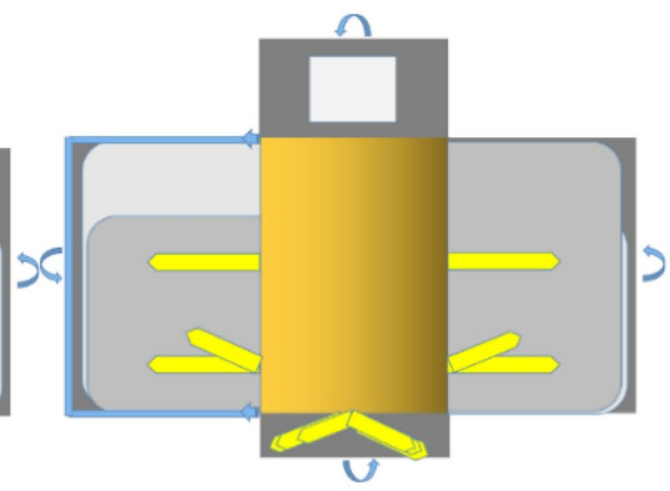

(b)

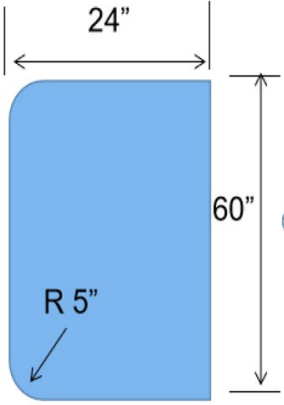

(a)

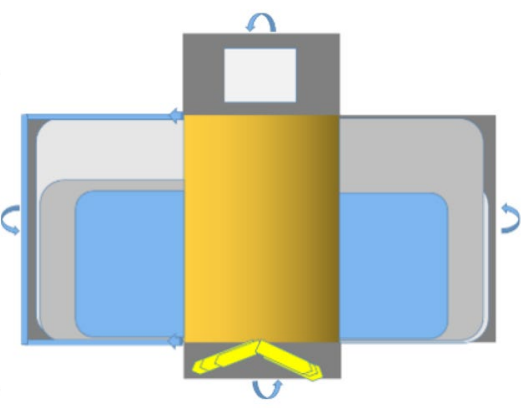

(b)
Fig. 7 a Dimension of cotton sheet layer (shown in blue) and (b) attachment of cotton sheet (blue) layers on either side of the PU foam layer

use appropriate PPE as advised in the national and international regulatory guidelines (WHO Interm Guidance 2020; Ministry of Health \& Family Welfare 2020; European Centre For Disease Prevention and Control 2020). The corpse will be placed upon a super-absorber layer of PU base. Then, a layer of the cotton sheet will also absorb any remnant body fluid spills. The reason for using PU and not just cotton sheet is that in case of a leakage of body fluid from the opening for cannulae and syringes, cotton may lose its integrity, whereas PU foam will not. Other characteristics that make the use of PU attractive over cotton are given in Table 2. Further, two layers of transparent plastic sheets are added one after the other to make the bag $100 \%$ leak-proof and impermeable. Finally, the outermost cover is a non-transparent plastic layer incorporated with a U-shaped zipper. The outermost plastic cover has 3 window-shape cutouts in the area, where the face of the dead body is kept. An extra margin of dimensions for the face window has been taken to compensate for a slight movement of the body. Therefore, in the manual process of insertion of the body of different heights into the body bag, the mortuary workers can adjust the placement of the body in such a way that closing of a body bag does not restrict the facial view of the cadaver. Thus, this will allow family members and relatives to view the face of the dead body without opening the body bag.

\section{Conclusions}

An integrated layered body bag design is an improvement over the conventional body bag to make it more suitable for situations like the Covid-19 virus epidemic. As per the proposal in design, it consists of a base layer of PU Foam, which acts as a super absorber layer, and whatever body fluid comes out of the body, gets efficiently absorbed by this layer. Two pairs of transparent plastic layers give extra protection from the direct contact of the bearer with the deceased body. Transparent plastic windows provide a provision to see the body face. Six handles of webbing strips give a provision to handle the body bag easily with care for safe handling, transportation, and disposal. The integrated body bag provides several benefits such as leak-proof, water resistance, easy to handle, capable of manufacturing locally, best fit for bio-hazardous situations, and can be burnt or buried along with the body while keeping everyone involved safe from the possibility of infections. 
Table 1 Figures depicting stepwise use of the aforementioned Body Bag

\begin{tabular}{|c|c|c|}
\hline 1. Insert deceased person & $\begin{array}{l}\text { 2. Cover one side of the cotton } \\
\text { sheet }\end{array}$ & $\begin{array}{l}\text { 3. Cover another side of cotton } \\
\text { sheet }\end{array}$ \\
\hline $\begin{array}{l}\text { 4. Fix cotton sheet using } \\
\text { Velcro strips }\end{array}$ & $\begin{array}{l}\text { 5. Cover one side of the } \\
\text { transparent } 1^{\text {st }} \text { layer }\end{array}$ & $\begin{array}{l}\text { 6. Cover another side of } \\
\text { transparent } 1^{\text {st }} \text { layer of plastic }\end{array}$ \\
\hline $\begin{array}{l}\text { 7. Fix transparent plastic } 1^{\text {st }} \\
\text { layer using Velcro strips }\end{array}$ & $\begin{array}{l}\text { 8. Cover one side of a } \\
\text { transparent } 2^{\text {nd }} \text { layer of plastic }\end{array}$ & $\begin{array}{l}\text { 9. Cover another side of } \\
\text { transparent } 2^{\text {nd }} \text { layer of plastic }\end{array}$ \\
\hline $\begin{array}{l}\text { 10. Fix transparent plastic } \\
2^{\text {nd }} \text { layer using Velcro strips }\end{array}$ & $\begin{array}{l}\text { 11. Cover bottom side of plastic } \\
\text { sheet on body }\end{array}$ & $\begin{array}{l}\text { 12. Cover one side of } \\
\text { outermost plastic covering on } \\
\text { the body }\end{array}$ \\
\hline $\begin{array}{l}\text { 13. Cov } \\
\text { the oute } \\
\text { layer on }\end{array}$ & $q^{q}(\cdot) p$ & $\begin{array}{l}\text { 14. Cover U shaped zipper } \\
\text { side of the outermost plastic } \\
\text { sheet on the body and zip it }\end{array}$ \\
\hline
\end{tabular}


Table 2 Comparison between cotton sheet versus PU Foam as the Bottom absorbing layer

\begin{tabular}{lll}
\hline Characteristics & Cotton layer & PU FOAM Layer \\
\hline $\begin{array}{l}\text { Moisture absorption } \\
\text { Softness and handling }\end{array}$ & $\begin{array}{l}\text { Absorbs moisture } \\
\text { Varies from product to product }\end{array}$ & Wicks absorbs moisture faster \\
& & $\begin{array}{c}\text { Very soft yet rigid and stiff enough (Diisocyanates are a } \\
\text { group of low molecular weight aromatic and aliphatic } \\
\text { compounds, widely used in the manufacturing of }\end{array}$ \\
Maintenance & Tends to wrinkle & Nolyurethanes) \\
Applications & Low gsm is used as finer bed sheets & Often used in mattresses \\
Cost price & Not available in required thickness. 275-350 gsm will not & Only Rs 1000 per bag (90 $\times 36$ in.) of 0.5 in. thickness \\
& be finer one to serve the purpose of lightweight along with & \\
& sufficient absorption capacity &
\end{tabular}

\section{References}

(2019) Interim Guidelines for Biosafety and COVID-19| CDC. https ://www.cdc.gov/coronavirus/2019-ncov/lab/lab-biosafety-guide lines.html

(2020a) Coronavirus complications: how Covid-19 effect your lungs. Narayana Health. https://www.narayanahealth.org/blog/how-covid -19-affect-your-lungs/

(2020b) Coronavirus Resource Center-Harvard Health. https://www. health.harvard.edu/diseases-and-conditions/coronavirus-resourcecenter

(2020c) Where we're at with vaccines and treatments for COVID-19. https://www.healthline.com/health-news/heres-exactly-where -were-at-with-vaccines-and-treatments-for-covid-19

(2020d) India Coronavirus, COVID-19 Live Updates, May 13: Record 202 new cases in 24 hrs take Rajasthan's total to 4,328; death count at 121 India News| Zee News. https://zeenews.india .com/india/live-updates/india-coronavirus-covid-19-live-updat es-may-13-record-202-new-cases-in-24-hrs-take-rajasthans -total-to-4328-death-count-at-121-2283094

(2020e) COVID-19 Estimates for Junel AIR Worldwide. https://www. air-worldwide.com/news-and-events/press-releases/estimates-forcovid-19/

(2020f) Coronavirus: Body-bag stocks 'in danger of running out'BBC News. https://www.bbc.com/news/health-52205655

(2020g) 'Mission Self-Reliant India': COVID-19 crisis opportunity, says PM Modi as he announces Rs 20 lakh crore package. https:// www.dnaindia.com/india/report-mission-self-reliant-india-covid -19-crisis-opportunity-says-pm-modi-as-he-announces-rs-20lakh-crore-package-2824591

(2020h) Almost 44 lakh global coronavirus COVID-19 cases, death count at 2.95 lakhl World Newsl Zee News. https://zeenews.india .com/world/almost-44-lakh-global-coronavirus-covid-19-cases -death-count-at-2-95-lakh-2283347.html

(2020i) Funeral body bags for dead bodies, funeral body bags for dead bodies Suppliers and Manufacturers at Alibaba.com. https://www. alibaba.com/showroom/funeral-body-bags-for-dead-bodies.html

(2020j) Thr-711 Ldpe Funeral Corpse Bag/body Bag-Buy Funeral Corpse Bag, Dead People Bag, Funeral Bag Product on Alibaba. com. https://www.alibaba.com/product-detail/THR-711-LDPEFuneral-Corpse-Bag_60047599212.html?spm=a2700.detai 1s.maylikeexp.9.31a037eaypsIz3

Bedford J (2018) Social science in humanitarian action. Key considerations: the context of North Kivu brief province, DRC, Brief, UNICEF, IDS \& Anthrologica 19:1-4
Cascella M, Rajnik M, Cuomo A, Dulebohn SC, Di Napoli R (2020) Features, evaluation and treatment coronavirus (COVID-19). In: Statpearls. StatPearls Publishing

Collins P (2013) Worldometers: real time world statistics. https://www. worldometers.info/weight-loss. Accessed 12 May 2020

European Centre For Disease Prevention and Control (2020) Considerations related to the safe handling of bodies of deceased persons with suspected or confirmed COVID-19 1-4. https://www.ecdc. europa.eu/sites/default/files/documents/COVID-19-safe-handl ing-of-bodies-or-persons-dying-from-COVID19.pdf. Accessed 12 May 2020

Gorbalenya AE et al (2020) The species and its viruses-a statement of the Coronavirus Study Group. Biorxiv (Cold Spring Harb Lab) 5:1-15. https://doi.org/10.1101/2020.02.07.937862

Key Points (2016) ADB Brief, No 59. https://www.adb.org/sites/defau 1t/files/publication/185618/social-welfare-mongolia.pdf. Accessed 12 May 2020

van Doremalen N et al (2020) Aerosol and surface stability of SARSCoV-2 as compared with SARS-CoV-1. N Engl J Med. https://doi. org/10.1056/NEJMc2004973

WHO (2020) World Health Organization. https://www.who.int/. Accessed 12 May 2020

WHO Interm Guidance (2020) Infection prevention and control for the safe management of a dead body in the context of COVID-19. J Hosp Infect 104:246-251

Wang D et al (2020) Clinical characteristics of 138 hospitalized patients with 2019 novel coronavirus-infected pneumonia in Wuhan, China. JAMA J Am Med Assoc 323:1061-1069

World Health Organization (2020) Modes of transmission of virus causing COVID-19: implications for IPC precaution recommendations. https://www.who.int/news-room/commentaries/detai 1/modes-of-transmission-of-virus-causing-covid-19-implicatio ns-for-ipc-precaution-recommendations. Accessed 12 May 2020

Ministry of Health \& Family Welfare-Government of India (2020). Covid19-Guidelines on dead body management. 1-7. https:// www.mohfw.gov.in/pdf/1584423700568_COVID19Guidelin esonDeadbodymanagement.pdf. Accessed 12 May 2020

Publisher's Note Springer Nature remains neutral with regard to jurisdictional claims in published maps and institutional affiliations. 